\title{
Patterns of Women's Enrolment in University Mathematics, Engineering and Computer Science in Canada, 1972-1995
}

\section{TAHANY M. GADALLA}

Ontario Institute for Studies in Education/University of Toronto

\section{ABSTRACT}

Efforts to ensure equity for women in scientific and technological disciplines must precede, or at least accompany, efforts to persuade them to pursue these studies. To achieve gender equity in these disciplines, factors discouraging women from full participation in them should be removed. Many psychological, sociological and institutional factors have been identified as contributors to the under-representation of women in these fields. For the aim of understanding and appraising these factors, this study offers a factual characterization of women's enrolment levels in mathematics, engineering, and computer science in Canadian universities and the change in these levels over the period 1972 to 1995. Findings indicate that patterns of women's enrolment in these three disciplines are vastly different, a fact which suggests that factors specific to each discipline interact with and modify the effects of the more general sociological and psychological obstacles impeding women's participation in them. 


\section{RÉSUMÉ}

Tout effort qui vise à assurer l'équité féminine dans les disciplines scientifiques et technologiques doit précéder, ou du moins accompagner, tout effort employé pour persuader ces femmes à poursuivre leurs études dans ces domaines. Pour que l'équité se réalise pleinement à travers ces disciplines, il est important que tout facteur qui puisse décourager la pleine participation féminine dans ces disciplines soit éliminé. Plusieurs éléments psychologiques, sociologiques et institutionnels ont déjà été identifiés comme étant des facteurs contribuant à la faible représentation féminine dans ces disciplines. Cette étude offre une représentation factuelle des niveaux d'inscriptions féminines ainsi que les changements dans ces niveaux au cours de la période partant de 1972 à 1995. Les résultats de cette étude démontrent de vastes différences entre les niveaux $d$ 'inscriptions féminines de discipline en discipline, ce qui suggère que des facteurs propres à chaque discipline s'entremêlent et modifient les aspects plus généraux des obstacles sociologiques et psychologiques qui empêchent la pleine participation féminine dans ces domaines.

\section{INTRODUCTION}

In 1982, the Science Council of Canada published The Science Education of Women in Canada: A statement of concern indicating the federal government's recognition of the serious under-representation of girls in high school science and mathematics classes. Reasons for concern included not only the impact of lack of knowledge in mathematics and science on the lives and careers of women, but also its impact on the economic welfare of the country as a whole. Following the publication of the Science Council's "statement of concern" government agencies, professional associations, school boards, postsecondary institutions, businesses, and industries have promoted the implementation of, and in some cases adopted new programs specifically designed to increase young women's interests in mathematics and science, and encourage them to pursue careers in these fields. Remedial measures have been adopted to increase student awareness of the importance of taking mathematics courses, and means have been taken to combat the deleterious effects of mathematics 
anxiety and mathematics avoidance. Such programs range from career conferences which provide information regarding occupational opportunities to radical programs such as segregated mathematics classes. A handbook of fourteen existing intervention programs was compiled in 1988 by York University (York University, 1988).

In 1994, twelve years after the publication of the Science Council's "Statement of Concern," women remained very much a minority among professionals employed in the natural sciences, engineering and mathematics. In fact, just 19\% of professionals in these occupations in 1994 were women, a figure which has changed little since 1982 (15\%) (Statistics Canada, 1995). In addition, it is unlikely that female representation in these occupations will increase in the near future because women continue to account for relatively small proportions of total university enrolments in these fields (Statistics Canada, 1995).

Gender imbalance in the fields of mathematics, science and technology is an issue of educational equity. It raises the disturbing possibility that the education system functions in ways which discourage women from pursuing mathematical and scientific careers. If true, this situation is not only unethical, but it also closes an expanding job market to women and, hence, limits their career choices.

\section{REASONS FOR THE PAUCITY OF WOMEN IN SCIENCE AND TECHNOLOGY}

There is no single reason for the under-representation of women in mathematics, science and technology. Researchers have identified a variety of sociological, psychological, institutional and economic factors which interact in complex ways to deter women from pursuing careers in these fields (Brush, 1991; Chipman, 1996; Lawton \& Bordens, 1995).

High school mathematics courses have been declared a "critical filter" for screening women out of mathematics and science university programs and have long been blamed for the paucity of women in the scientific and technological work force (Wiggan, Kryger, Gamery, Morris, Clifford \& Getty, 1983). However, recent statistics indicate that large gender differences in enrolment in high school mathematics and 
science courses have disappeared (Chipman \& Thomas, 1985). Gender differences in mathematics and science achievement have received considerable attention from researchers as a potential reason for gender differènces in participation in these fields. However, studies using meta-analysis, such as the one carried out by Linn and Hyde (1989) and Hyde, Fennema, and Lamon (1990), concluded that: (1) gender differences in mathematics achievement are not evident prior to high school; (2) gender differences in mathematics achievement have declined; (3) gender differences in cognitive and psychosocial tasks are small and declining; and (4) gender differences in cognitive processes often reflect differences in course enrolment and training.

Psychological processes such as attributional patterns and lack of confidence in themselves as learners of mathematics are also suggested as possible inhibitors of female achievement. In a review of the literature on gender attributional patterns in relation to mathematics achievement, Leder (1992) states that when differences are found, females are more likely than males to attribute success to effort and failure to lack of ability and that attribution of failure to lack of ability is unlikely to yield a belief in a high likelihood of a future success. Stipek and Gralinski (1991) also found that elementary and junior high school girls were less confident than boys that they would do well on a mathematics test they were about to take, in spite of the fact that their grades were similar.

Environmental factors such as parents' attitudes, teachers' attitudes, teaching methods, student-teacher interaction, lack of female role models, competing family responsibilities, chilly climate, and feelings of isolation are also indicated as having negative effects on women's participation in these fields. Rosser (1990), for example, argues that teaching practices that emphasize competitiveness and rapid solving of problems and those that depict careers in science as being overly demanding, discourage women. Lack of supportive environments, both in the classroom and in the work place, is indicated by numerous examples of negative attitudes toward women engineers and computer scientists (Brush, 1991; Canadian Committee on Women in Engineering, 1992). Other factors used to explain women's low participation in technological fields are the gender bias and stereotyping found in recreational and educational software 
programs, and the fact that boys have more exposure to computers at home and in computer camps (Pearl, Pollack, Riskin, Thomas, Wolf \& Wu, 1990).

Research done in the area of interest and mathematics is based on the conviction that students' interest in learning mathematics is important, that mathematics curricula and teaching strategies should stimulate and expand students' interests, and that the situational interest triggered by environmental factors may evoke or contribute to the development of long-lasting individual interests (Hidi, 1990). Explanations offered for the gender differences in science and technology interests vary between the notion that gender identity is formed in infancy at a deep psychological level (Harding \& Sutoris, 1987) and the notion that gender roles are socially constructed and are influenced by political and economic agendas (Alloway, 1995).

Feminist theories come in a variety of shades and examine the nature of mathematics and science and possible gender differences in learning styles. Demographic and economic factors such as cohort size, family income and rate of return are proposed by educational economists as possible explanations for men's and women's decisions about career choices (Denton \& Spencer, 1992; Freeman, 1986; Foot \& Pervin, 1983). A more comprehensive review of the studies done on the factors affecting women's participation in mathematics, science and technology and of the theories relating these factors to enrolment is given by Gadalla (1998).

\section{OBJECTIVES}

The aim of this study is to examine and compare women's participation in mathematics, engineering and computer science programs at the bachelor, masters and doctoral levels in Canadian universities over the period 1972-73 to 1994-95. Women's current representation in each of these disciplines, as well as the extent of change in their enrolment over the study period, are compared with (1) men's enrolment in the specific discipline during the same time period, and (2) women's enrolment in all university programs during the same time period. The flow of students through the education system in each of the three disciplines 
is investigated with the objective of locating road blocks hindering women's progress in these fields. Attempts are made to isolate discipline-specific changes and gender-specific changes from more general demographic and social trends. Patterns of women's enrolments in mathematics, computer science and engineering are compared.

The factual characterization of the magnitude of the gender gap in these three disciplines, of the change, if any, in this magnitude over time, and of the differences and similarities in the participation of women in various scientific disciplines is an essential first step toward understanding and appraising the reasons behind the paucity of women in these fields.

Because the extent of the gender imbalance is not uniform across scientific disciplines and because these disciplines also vary in their curricula and the type of occupations to which they lead, causes of the low participation of women in these disciplines might also vary. Hence, there is the need for separately examining women's enrolment rates in mathematics, engineering and computer sciences. In addition, the analysis of women's progress through the education levels will enable us to determine at which education level women's progress is impeded in each of these disciplines. Knowing where in the education system these barriers might lie is a primary step on the road to removing them.

For the last two decades, many intervention projects have been carried out to increase young women's interests in mathematics and science and to convince them to seek careers in these fields. An example of such projects is W.I.S.H. (Women In Science, Hopefully), which was initiated in 1984 at York University, and was funded by the Ontario Women's Directorate. Little effort has been made to evaluate the effectiveness of these projects and to assess their outcomes. Monitoring the change in women's presence in mathematics and science programs over a period of 23 years will give an accurate picture of the progress to date, hence contribute to the evaluation of these intervention efforts.

The study of past trends in enrolment provides a basis for future projections of university enrolment and of labour force supply of specific professions. These projections are used by labour market analysts. They also provide educational policy makers with information that can be used in allocating resources to various sectors of the education system. 


\section{DATA AND METHODS}

Data collected by Statistics Canada on university enrolment at the bachelor, masters and doctoral levels, broken down by registration status, gender, and field of study, for the years 1972-73 to 1994-95, were analysed for this paper. The year 1972-73 was the first year in which Statistics Canada collected university enrolment data with a breakdown by gender. As defined by Statistics Canada, mathematics programs include pure and applied mathematics, statistics and actuarial science programs. Engineering programs include chemical, civil, electrical, mechanical, and other engineering. Parity indices and adjusted participation rates were used in this work in an attempt to disentangle disciplinespecific and gender-specific changes from the more general trend of increased enrolments in Canadian universities.

\section{FINDINGS}

\section{Enrolment in All Programs}

Numbers of women and men enrolled in all programs in Canadian universities by level of study during the period 1972-73 to 1994-95 are plotted in Figure 1. This figure shows that women's enrolment in university programs at all three levels increased steadily during the study period, and at a much steeper rate than men's enrolment. Since 1982, more women than men have been opting for university education. In 1994-95, 24\% of women aged 20-24 attended a bachelor program, compared with $18 \%$ of men. The number of female university students in 1994-95 was $239 \%$ that in 1972-73. In recent years, university enrolment rates stabilized at their 1992 peaks. Figure 1 also shows a persistent gender gap in enrolment in doctoral programs which has not changed since 1982.

Table 1 displays data on part-time and full-time enrolment in all programs by gender and level of study in the first and the last year of the study period. The table shows that university enrolment grew from 389,793 in $1972-73$ to 690,713 in 1994-95, a growth of about $77 \%$. Women's share of enrolment in all programs at the bachelor level grew 
Figure 1

Total University Enrolment by Gender, Canada 1972-1994
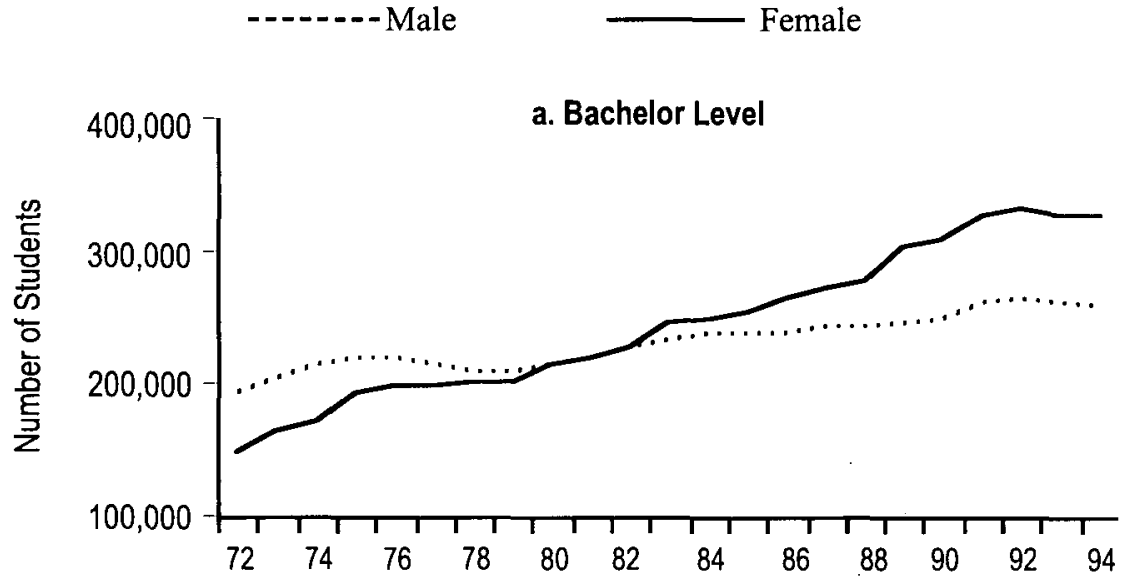
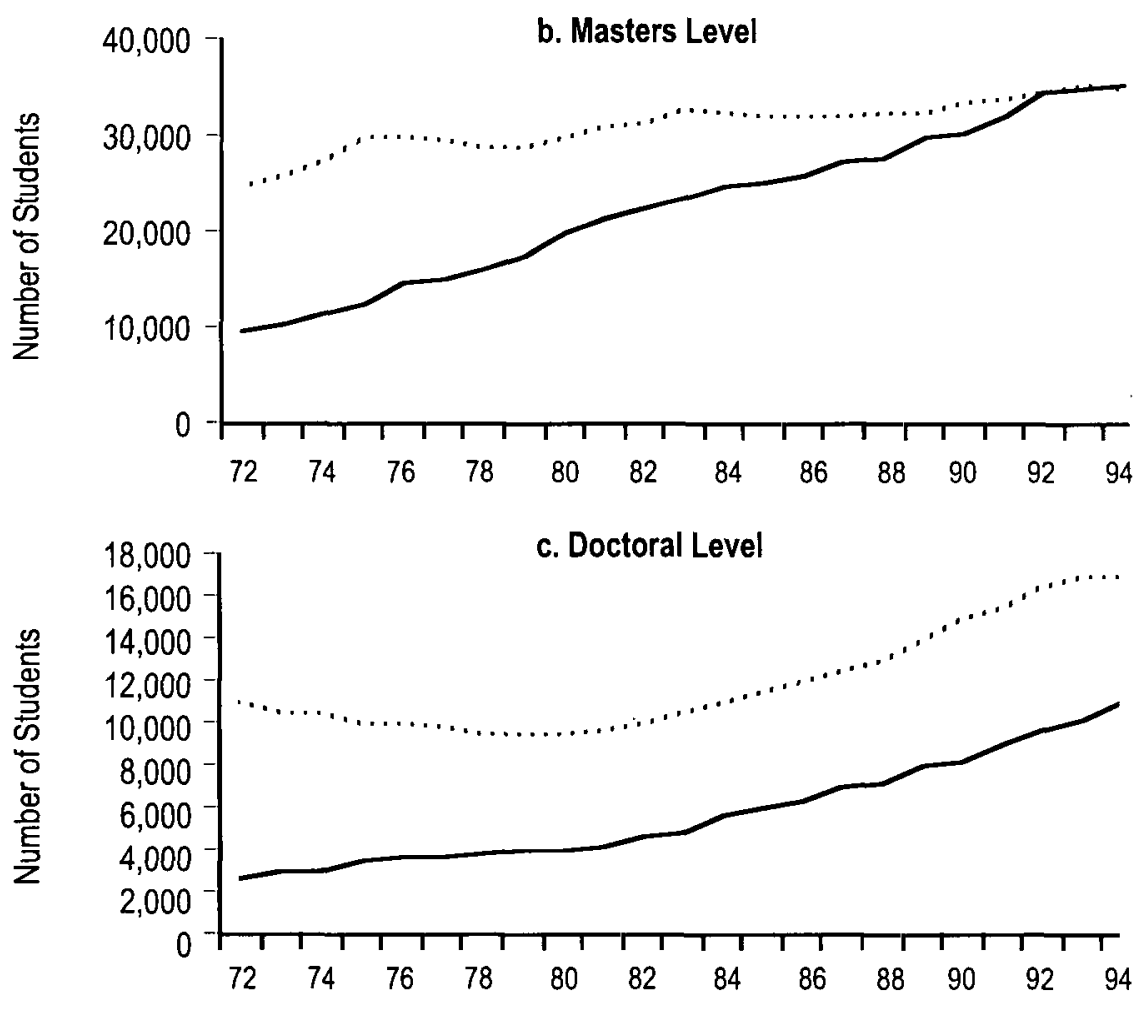

The Canadian Journal of Higher Education

Volume XXXI, No. 1, 2001 
Patterns of Women's Enrolment in University Mathematics, Engineering and Computer Science in Canada

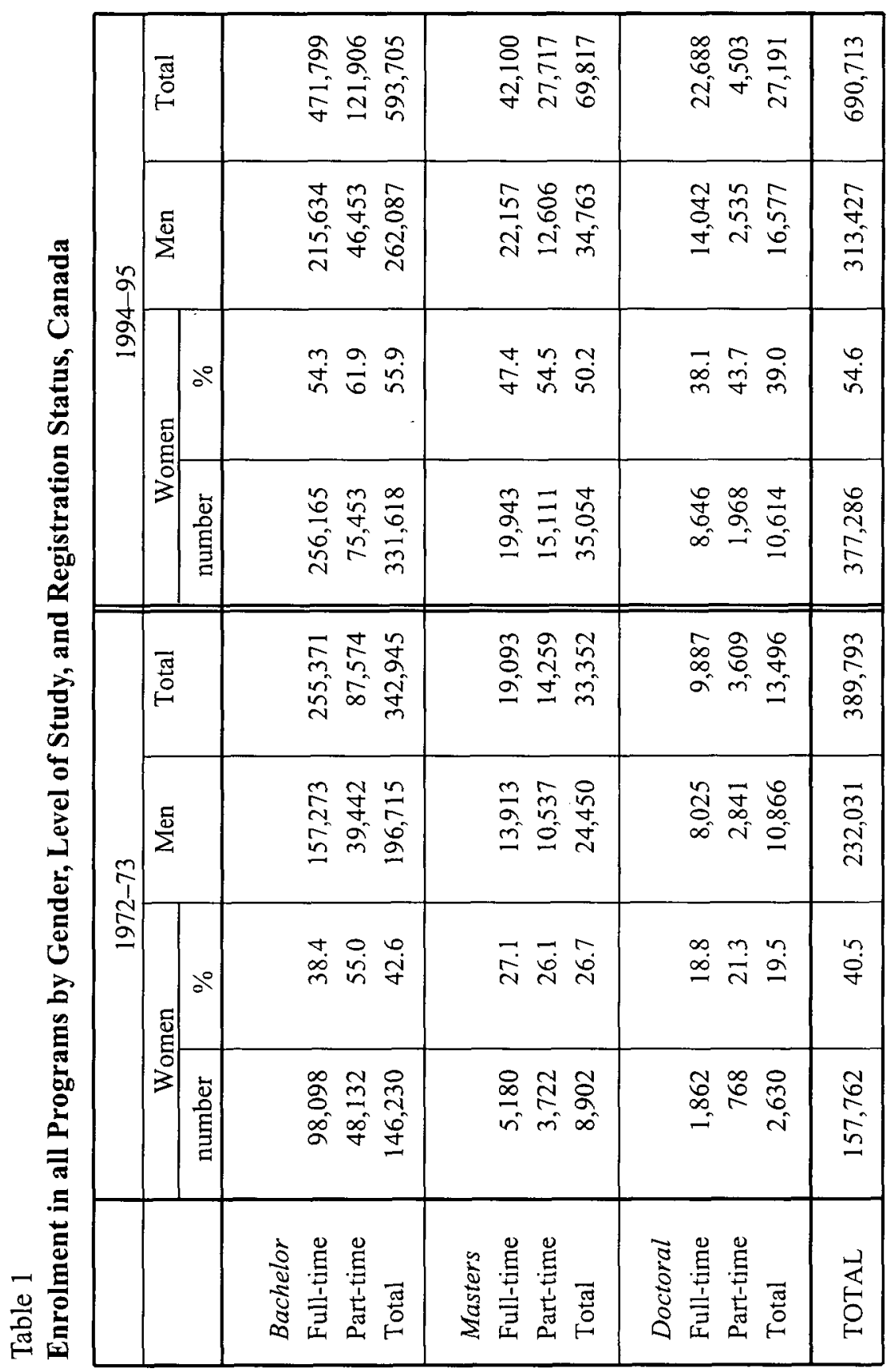

The Canadian Journal of Higher Education Volume XXXI, No. 1, 2001 
from $42.6 \%$ in $1972-73$ to $55.9 \%$ in $1994-95$ while their share of enrolment at the graduate levels almost doubled. At the present time, $56 \%$ of students in bachelor programs are women, enrolment in masters programs is split evenly between women and men, and in doctoral programs, $39 \%$ are women. That is, women's share of enrolment decreases as the level of study increases. At the three levels combined, women's enrolment increased from $40.5 \%$ in $1972-73$ to $54.6 \%$ in $1994-95$.

Data in Table 1 also indicate that in 1972-73, part-time students accounted for $25 \%$ of total enrolment at the bachelor level, $43 \%$ at the masters level, and $27 \%$ at the doctoral level. In 1994-95, these percentages dropped to $21 \%$ of total enrolment at the bachelor level, $40 \%$ at the masters level, and $17 \%$ at the doctorate level. In other words, more students are pursuing their university study on a full-time basis. Also, women's representation is higher among part-time students compared to full-time students.

\section{Enrolment in Mathematics Programs}

Table 2 provides data on 1972-73 and 1994-95 enrolment in mathematics programs by gender, level of study and registration status. As seen in this table, the number of students in mathematics programs increased considerably over the study period. Women's share of mathematics enrolment at both the bachelor and the masters levels increased by approximately $10 \%$ and at the doctoral level by about $13 \%$. At the three levels combined, women's share of enrolment in mathematics increased from $28.5 \%$ in $1972-73$ to $38.2 \%$ in $1994-95$. Table 2 also shows that the number of female mathematics students in 1994-95 was $187 \%$ that in $1972-73$.

Parity Indices. During the last three decades women have been swelling the ranks in university programs at all levels. In order to isolate the trend toward women's increased presence in mathematics from the more general trend of their increased presence in university education, parity indices for women and men at each level of study are computed and compared. Parity index is the number of students in a specified discipline expressed as a percentage of the number of students in all programs. Differences in the shapes of the parity index curves for women 
Patterns of Women's Enrolment in University Mathematics, Engineering and Computer Science in Canada

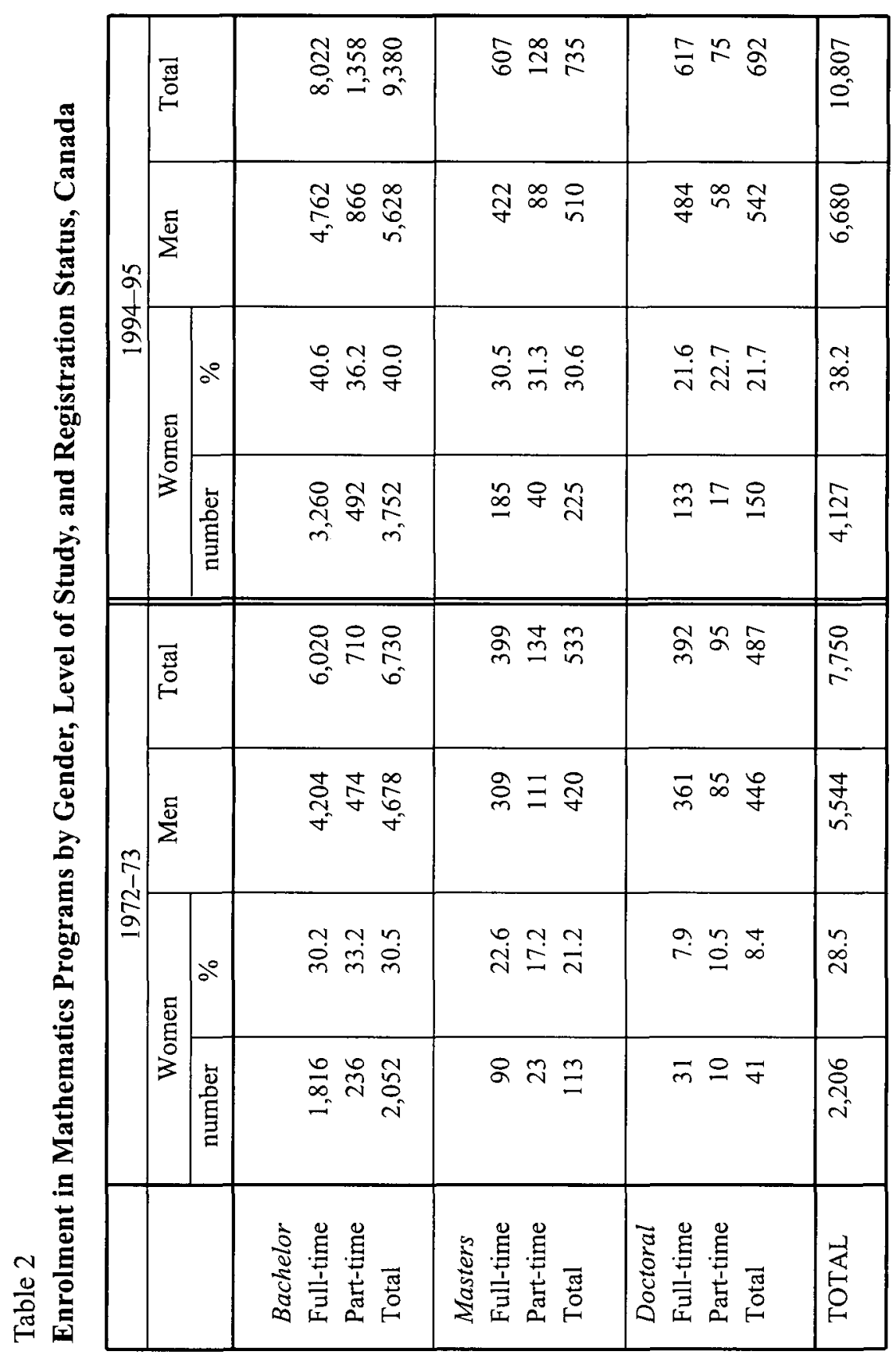

The Canadian Journal of Higher Education Volume XXXI, No. 1, 2001 
and men indicate gender differences in their tendency toward enrolling in mathematics.

Mathematics parity indices for women and men during the study period are displayed in Figure 2. In general, the figure reveals slightly negative mathematics-specific changes and gender-specific changes in men's favour. At the bachelor level, the parity index curves for women and men show similar, periodic changes over the study period. Men's and women's parity rise, fall, and level off over the same time periods. This finding suggests that they are reacting to the same set of social and economic factors in the same direction. Both curves have been on the decrease since 1986 indicating that the likelihood of a bachelor student, of either sex, majoring in mathematics is on the decline.

While women's representation in masters level programs in general increased, mathematics share of masters level students decreased. Mathematics parity for men at the masters level dropped very slightly over the study period.

The most striking feature of the women's doctoral index curve is the apparent lack of trend over the study period. Women's enrolment in mathematics doctoral programs has been fluctuating around $1.3 \%$ of all women's doctoral enrolment; the corresponding percentage for men during the last six years is $3.5 \%$, which is almost two and a half times that of women.

In summary, at the three levels of study, mathematics was losing students of both sexes to other programs during the period 1972 to about 1978 , and although the field made some gains, the proportion of university students who are in mathematics never rose back to its 1972 levels. This is particularly true at the masters level.

Adjusted Participation Rate. Adjusted participation rate provides another way of looking at the progress women made in venturing into fields perceived by many as male areas. It can also be expressed as the proportion between the sex ratio of mathematics students and that of all university students. Based on the assumption that women and men are able to achieve equally in mathematics, the sex ratio in mathematics should be equivalent to that in the student population in all fields. Thus, the difference between this rate and one is a measure of the disparity in 
Figure 2

Mathematics Parity Index by Gender, Canada 1972-94

-.---.-- Male

Female
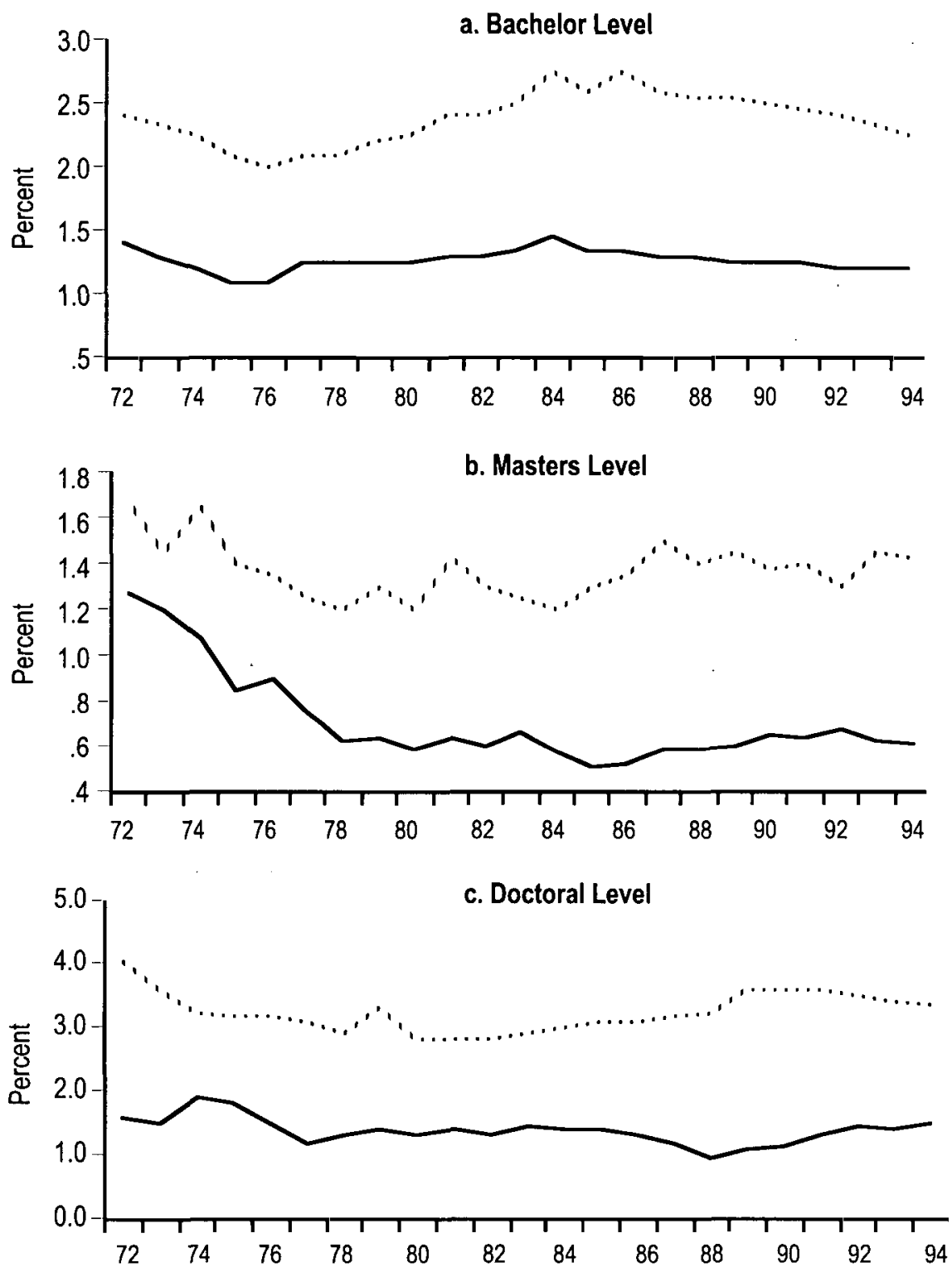

The Canadian Journal of Higber Education Volume XXXI, No. 1, 2001 
the rates at which women and men major in mathematics. Adjusted participation rates at each of the three levels of study are displayed in Figure 3. The figure shows that the bachelor participation rate exhibits a slight downward trend, from $59 \%$ in $1972-73$ to $53 \%$ in $1994-95$, the masters rate a more noticeable downward trend, from $74 \%$ in $1972-73$ to $44 \%$ in 1994-95, and the doctoral rate has been fluctuating around the $40 \%$ mark. These results are not in concordance with the reported large increase in mathematics enrolment at the high school level.

Women's Enrolment at the Present Time. Data in Tables 1 and 2 suggest the following points regarding enrolment in mathematics programs at the present time:

1. The proportion of students of both genders enrolled in mathematics programs is very low. Of a total of 690,713 students on campus, only 10,807 are studying mathematics, that is less than $1.6 \%$. It is worth noting that the proportion of students of both genders enrolled in mathematics doctoral programs in $1994-95,2.5 \%$, is higher than their proportions at the bachelors and masters levels, $1.6 \%$ and $1.1 \%$ respectively

2. Mathematics is still predominantly a male field, especially at the graduate level, with men occupying approximately 7 out of every 10 masters level seats and 8 out of every 10 doctorate seats.

3. Female to male ratio in mathematics is about one half of the female to male ratio in all programs. That is, women are only about half as likely as men to major in mathematics. This likelihood is slightly higher at the bachelor level (53\%), and lower at the masters and the doctoral levels ( $44 \%$ and $43 \%$ respectively).

Women's Movement Through Levels of Study. Women's share of mathematics enrolment at the three levels of study are $40 \%, 30.6 \%$, and $21.7 \%$, a drop of about 9 percentage points with each higher level (Table 2). Women's share of total university enrolment decreases by about 6 percentage points from $55.9 \%$ to $50.2 \%$ as they move up from the bachelor to the masters level, and by about 11 percentage points as they move to the doctorate level (Table 1). 
Figure 3

Adjusted Participation Rate in Mathematics by Level of Study, Canada 1972-1994

Bachelor

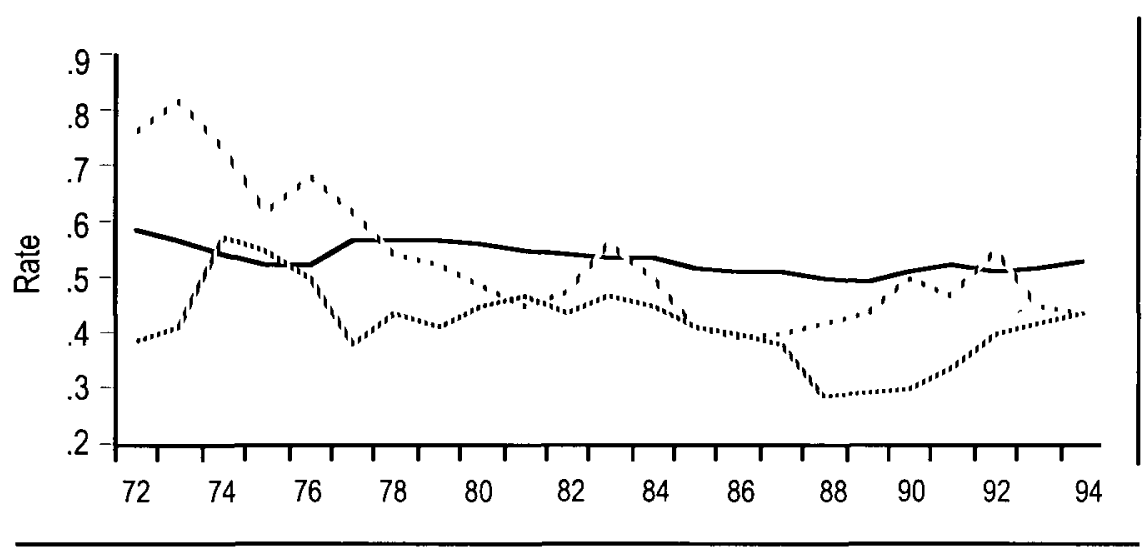

\section{Enrolment in Engineering Programs}

Table 3 provides data on 1972-73 and 1994-95 enrolment in engineering programs by gender, level of study and registration status. As seen in this table, the number of engineering students more than doubled over the study period. The number of women engineering students rose from 441 in $1972-73$ to 9,805 in 1994-95. This corresponds to a tenfold rise in women's share of engineering enrolment, from $1.8 \%$ in $1972-73$ to $17.9 \%$ in $1994-95$ with the highest increase at the bachelor level, from $1.7 \%$ in $1972-73$ to $18.4 \%$ in $1994-95$, and the lowest increase at the doctoral level from $2.7 \%$ in $1972-73$ to $10.4 \%$ in 1994-95. It is interesting to note that women's share of masters and doctoral enrolment in 1972-73 was higher than their share of bachelor enrolment. This means that as early as 1972 , those very few women who majored in engineering tended to persevere in this field and advanced to graduate levels in greater numbers than their men peers. In 1994-95, women's portion of bachelor and masters enrolment were about equal at $18.4 \%$ and $18.5 \%$ respectively and was 8 percentage points lower, at $10.4 \%$, of doctoral seats. 


\begin{tabular}{|c|c|c|c|c|c|c|c|c|}
\hline & & & & & & & & \\
\hline & Wc & & Men & Total & & & Men & Total \\
\hline & number & $\%$ & & & number & $\%$ & & \\
\hline $\begin{array}{l}\text { Bachelor } \\
\text { Full-time } \\
\text { Part-time } \\
\text { Total }\end{array}$ & $\begin{array}{r}322 \\
15 \\
337\end{array}$ & $\begin{array}{l}1.7 \\
1.8 \\
1.7\end{array}$ & $\begin{array}{r}19,015 \\
799 \\
19,814\end{array}$ & $\begin{array}{r}19,377 \\
814 \\
20,151\end{array}$ & $\begin{array}{r}7,638 \\
503 \\
8,141\end{array}$ & $\begin{array}{l}18.8 \\
13.7 \\
18.4\end{array}$ & $\begin{array}{r}32,975 \\
3,180 \\
36,155\end{array}$ & $\begin{array}{r}40,613 \\
3,683 \\
44,296\end{array}$ \\
\hline $\begin{array}{l}\text { Masters } \\
\text { Full-time } \\
\text { Part-time } \\
\text { Total }\end{array}$ & $\begin{array}{l}49 \\
17 \\
66\end{array}$ & $\begin{array}{l}2.8 \\
1.6 \\
2.3\end{array}$ & $\begin{array}{l}1,723 \\
1,060 \\
2,783\end{array}$ & $\begin{array}{l}1,772 \\
1,077 \\
2,849\end{array}$ & $\begin{array}{r}989 \\
286 \\
1,275\end{array}$ & $\begin{array}{l}19.6 \\
15.6 \\
18.5\end{array}$ & $\begin{array}{l}4,061 \\
1,546 \\
5,607\end{array}$ & $\begin{array}{l}5,050 \\
1,832 \\
6,882\end{array}$ \\
\hline $\begin{array}{l}\text { Doctoral } \\
\text { Full-time } \\
\text { Part-time } \\
\text { Total }\end{array}$ & $\begin{array}{r}32 \\
6 \\
38\end{array}$ & $\begin{array}{l}2.8 \\
2.3 \\
2.7\end{array}$ & $\begin{array}{r}1,110 \\
250 \\
1,360\end{array}$ & $\begin{array}{r}1,142 \\
256 \\
1,398\end{array}$ & $\begin{array}{r}370 \\
19 \\
389\end{array}$ & $\begin{array}{r}10.8 \\
6.1 \\
10.4\end{array}$ & $\begin{array}{r}3,044 \\
295 \\
3,339\end{array}$ & $\begin{array}{r}3,414 \\
314 \\
3,728\end{array}$ \\
\hline TOTAL & 441 & 1.8 & 23,957 & 24,398 & 9,805 & 17.9 & 45,101 & 54,906 \\
\hline
\end{tabular}


It is also apparent from Table 3 that most of the increase in women's enrolment happened in full-time enrolment. Furthermore, contrary to the situation in all disciplines where women comprise the majority of parttime enrolment, their share of part-time engineering enrolment is approximately 5 percentage points lower than their share of full-time enrolment at all three levels of study.

Parity Indices. Engineering parity indices, i.e., proportion of students in engineering to students in all disciplines, during the study period are displayed in Figure 4. In general, the figure reveals positive engineering specific changes for both sexes at all three levels of study indicating that the likelihood of a university student of either sex majoring in engineering increased over the duration of the study. In addition, the fact that the parity indices for women and men exhibit different shapes reveal definite gender specificity. In particular, at all three levels of study, the engineering share of university female students increased slightly and steadily during the whole period, while the engineering share of male students had its ups, downs and plateaus with an overall upward trend steeper than that of women. Dissimilarities in the shapes of the parity curves for women and men together with the failure of women's parity indices to increase as much as men's suggest that men's and women's engineering enrolments were reacting to a dissimilar set of influences.

At the bachelor level, the engineering share of male students increased sharply between 1974 and 1979, decreased slowly during the 1980 s and increased very slightly in the 1990 s. The proportion of engineering bachelor male students to all bachelor students rose from $10.1 \%$ in 1972-73 to an all time high of $14.5 \%$ in 1980 and reached $13.8 \%$ in 1994-95, while the proportion for female students rose steadily from $0.2 \%$ in $1972-73$ to a mere $2.5 \%$ in $1994-95$.

At the masters level, engineering share of male students was $11.4 \%$ in 1972-73. It fluctuated over the study period and reached $16.1 \%$ in 1994-95. The engineering share of female masters students rose from $0.7 \%$ in $1972-73$ to $3.6 \%$ in $1994-95$.

At the doctoral level, both men's and women's parity curves show lack of apparent trend during the 1970s followed by a steady, moderate increase during the 1980 s and the 1990 s with the men's index rising much 


\section{Figure 4}

Engineering Parity Index by Gender, Canada 1972-94

-.....- Male

Female
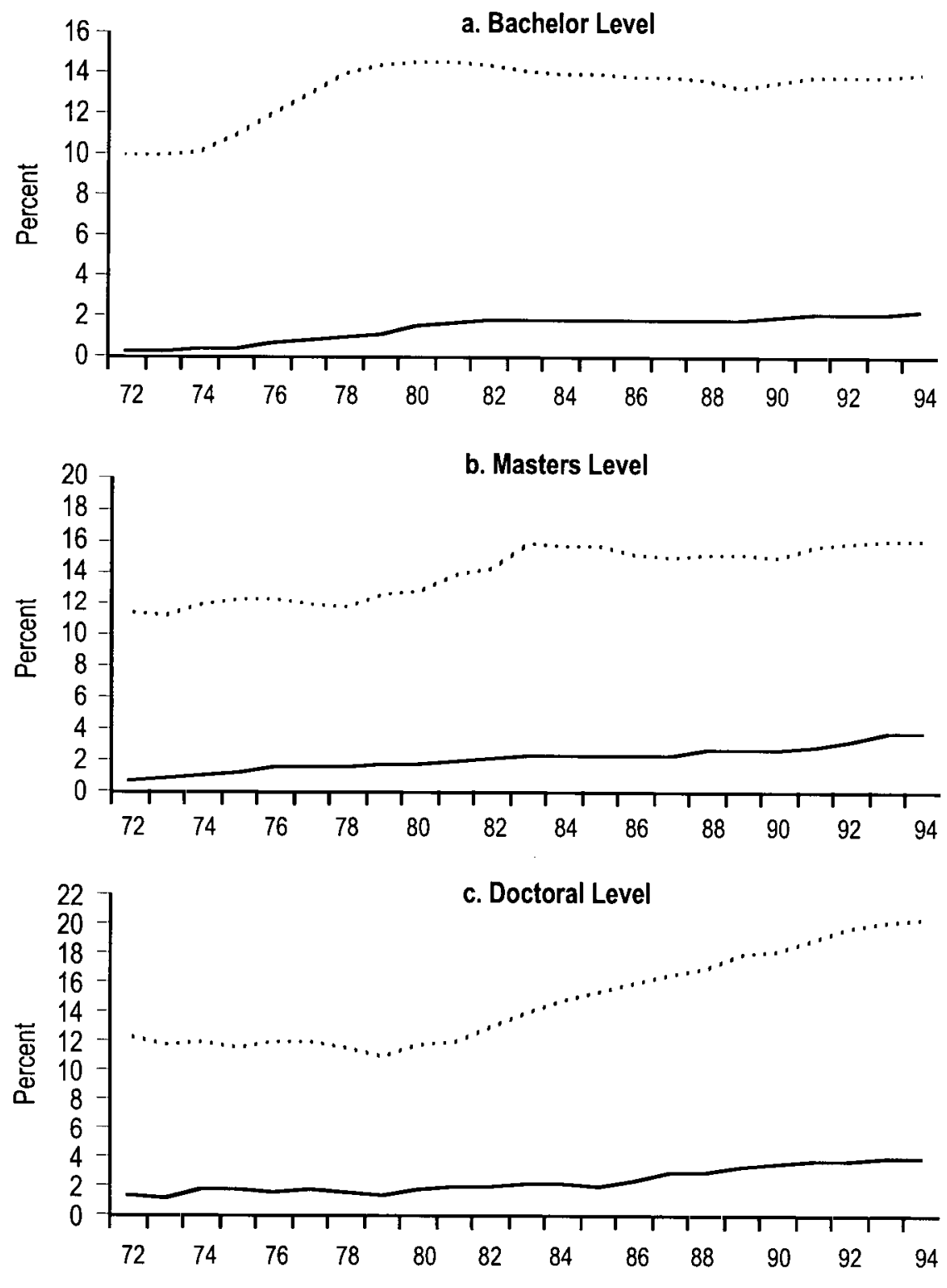

The Canadian Journal of Higher Education

Volume XXXI, No. 1, 2001 
faster than the women's. As a result, the gap between the two curves widens. Men's share of doctoral enrolment rose from $12.5 \%$ to $20.1 \%$ over the study period while women's share rose from $1.4 \%$ to $3.7 \%$.

Adjusted Participation Rates. Adjusted participation rates in engineering at the three levels of study are displayed in Figure 5. The most striking feature of this figure is the upward trends at the bachelor and masters levels over the whole study period. The figure shows that the bachelor participation rate grew from $2 \%$ in $1972-73$ to $18 \%$ in $1994-95$ and the masters rate grew from $7 \%$ to $23 \%$, while the doctoral rate grew from $12 \%$ to $18 \%$. Adjusted participation rate at the doctoral level shows the most fluctuation, less overall increase and a plateau since 1989 to the present. Adjusted participation rate at the three levels combined rose from $2.7 \%$ to $18.1 \%$ over the study period. In other words, although the likelihood of a female university student majoring in engineering relative to that of a man increased about seven-fold over the study period, a female university student is still only $18 \%$ as likely as a male university student to major in engineering.

Engineering Enrolment at the Present Time. Of both sexes on Canadian campuses, $8 \%$ study engineering. This percentage is higher at the graduate levels than at the bachelor level. In particular, $10 \%$ of masters students and $14 \%$ of doctoral students study engineering while only $7 \%$ of bachelor students do. This means that a greater proportion of engineering students remain in the education system compared to students in other fields.

Engineering is a predominantly male field. As shown in Table 3, women make up $17.9 \%$ of all engineering students: $18.4 \%$ at the bachelor level, $18.5 \%$ at the masters level, and $10.4 \%$ at the doctoral level. In spite of the ten-fold rise in women's share of engineering enrolment, the female-to-male ratio in engineering is still less than one-fifth of the female-to-male ratio in all fields of study. Put another way, the likelihood that a female university student will major in engineering is less than one-fifth that of a man.

Women's Movement Through Levels of Study. As shown in Table 3, women's share of engineering enrolment at the bachelor and masters levels are very similar, i.e., $18.4 \%$ and $18.5 \%$, while their share 
Figure 5

\section{Adjusted Participation Rate in Engineering by Level of Study,} Canada 1972-1994

Bachelor

-.---Masters

Doctoral

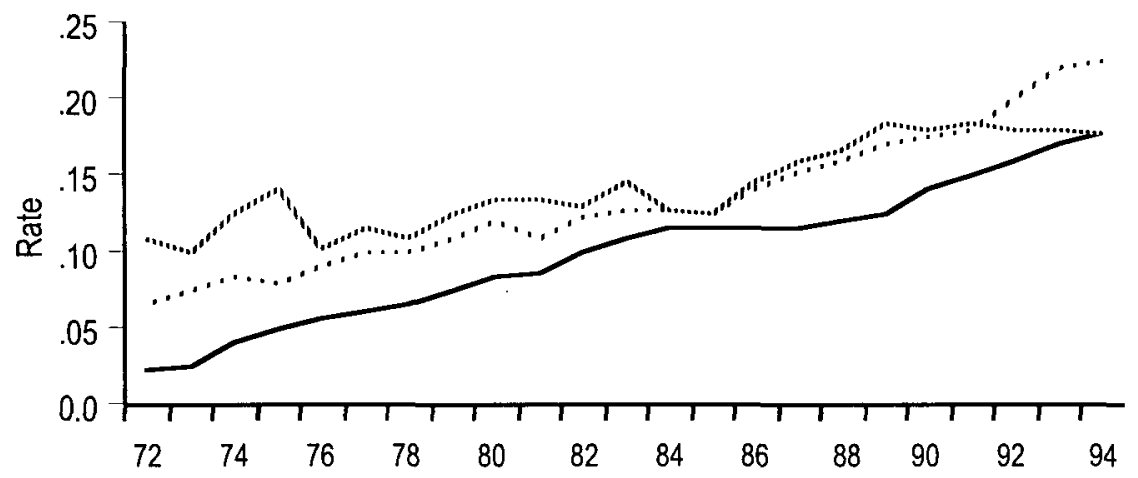

at the doctoral level is $10.4 \%$. This indicates that although graduate engineering programs do not lose women at entry into the masters level, they lose them at entry to the doctoral level

\section{Enrolment in Computer Science Programs}

The numbers of students enrolled in computer science programs in 1972-73 and 1994-95 broken down by gender, level of study and registration status are presented in Table 4. This table shows that women's portion of computer science enrolment hardly changed over the last 23 years. In 1994-95, women occupied $20.2 \%$ of all computer science places compared with $18.6 \%$ in $1972-73$. At the bachelor level women's portion was $20.2 \%$ in both years. At the masters level, women's enrolment rose from $13.6 \%$ in $1972-73$ to $22.6 \%$ in $1994-95$ whereas at the doctoral level, it rose from $5.3 \%$ to $16.2 \%$ during the same period. Most of the increase in women's bachelor enrolment took place in part-time enrolment. Women's portions of part-time bachelor and doctoral enrolment are higher than their portions in full-time enrolment. 
Patterns of Women's Enrolment in University Mathematics, Engineering and Computer Science in Canada

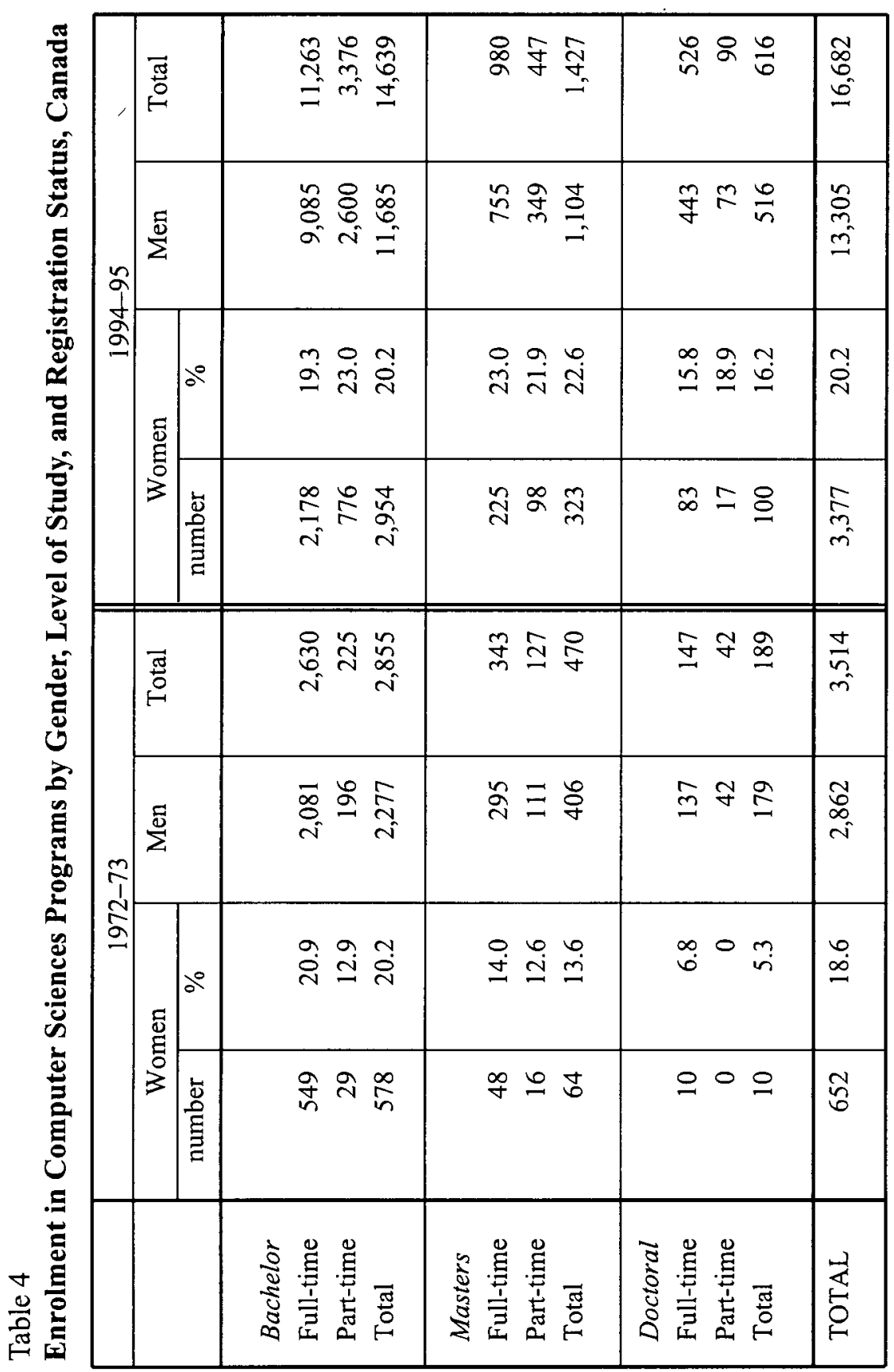

The Canadian Journal of Higher Education Volume XXXI, No. 1,2001 
Parity Indices. Men's and women's enrolment in computer science programs as a proportion of their total university enrolment are plotted in Figure 6. A noticeable characteristic of this figure is the expansion in the gender gap in enrolment at all levels of study which started in 1980 in bachelor enrolment and in 1982 in graduate programs. This expansion is the result of a faster rise in men's enrolment compared to women's enrolment, the latter showing modest increases over the study period. In 1994-95, 2.4\% of students in Canadian universities majored in computer science compared with $0.9 \%$ in $1972-73$. Almost all of the increase in computer science bachelor and masters enrolment took place in the late 1970 s and early 1980s. In doctoral programs, most of the increase took place in the second half of the 1980s. This increase, however, was not the same for women and men

Bachelor parity curves demonstrate a curious trend; they peaked in 1984, decreased sharply between 1984 and 1988, remained stable in the late 1980s, and increased moderately in the 1990s. The gender gap in computer science enrolment at the bachelor level expanded markedly in the $1980 \mathrm{~s}$ and $1990 \mathrm{~s}$. While $1.2 \%$ of male and $0.4 \%$ of female university students majored in this field in 1972-73, the corresponding percentages in 1994-95 were 4.2 and 0.9 . This corresponds to a 2.25 -fold increase for women and 3.5-fold increase for men. The gender gap in enrolment in graduate programs also expanded but to a lesser extent than it did in bachelor programs. For example, proportions of women and men masters students studying computer science in $1972-73$ were $0.7 \%$ and $1.7 \%$; in $1994-95$, they were $0.9 \%$ and $3.2 \%$. Proportions of female and male doctoral students studying computer science increased from $0.4 \%$ and $1.6 \%$ in $1972-73$ to $0.9 \%$ and $3.1 \%$, respectively, in $1994-95$. This corresponds to a roughly two-fold increase for men and 1.5-fold increase for women in graduate programs. It is thus evident that at all three levels of study, changes in the women's parity index echo changes in the men's parity index in direction although the changes are less dramatic in magnitude. This suggests that gender-specific factors might be causing women's enrolment to be less responsive than men's to economic and social factors which influence enrolment in this discipline. 


\section{Figure 6}

\section{Computer Science Parity Index by Gender, Canada 1972-94}

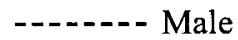

Female
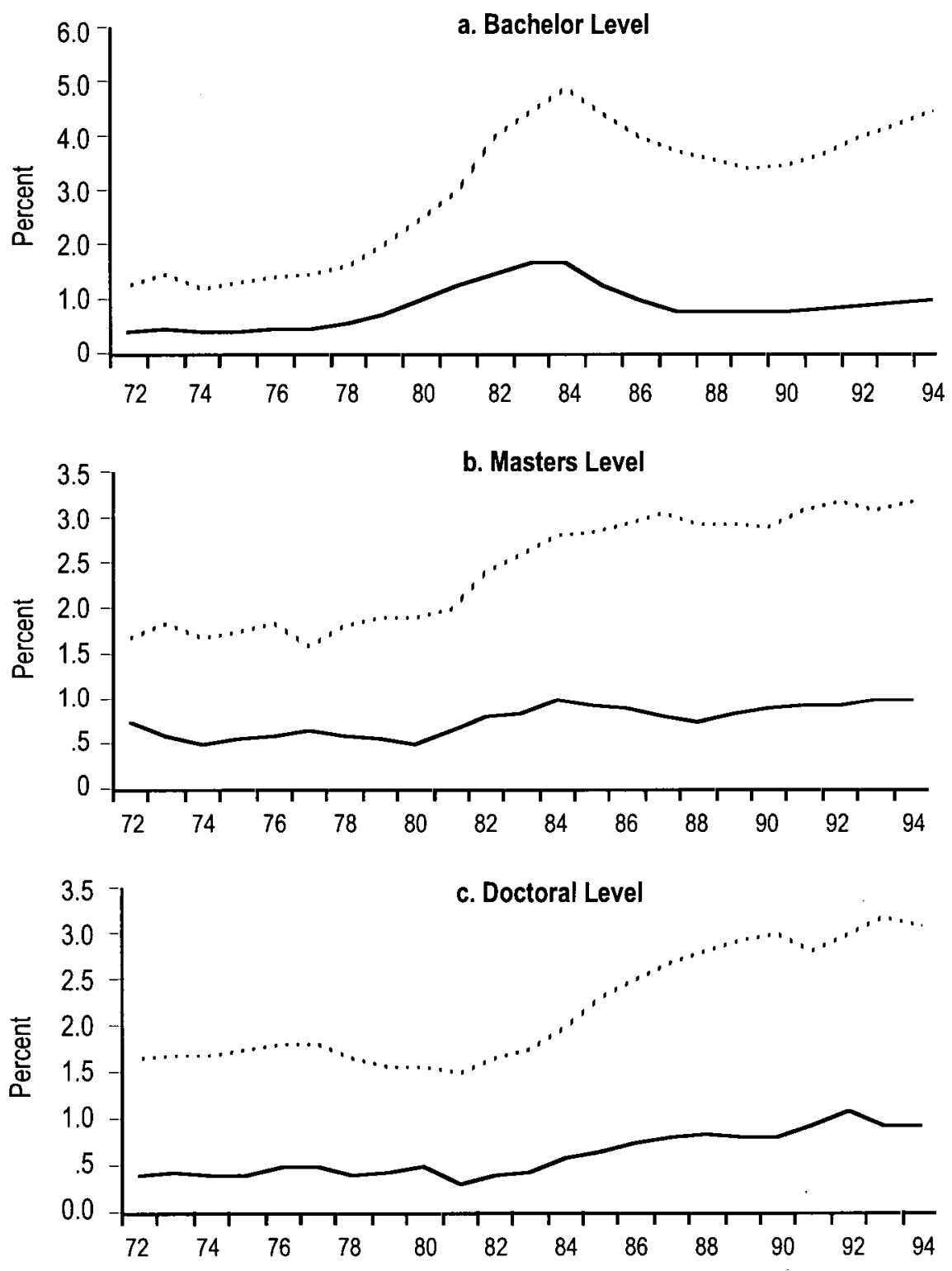

The Canadian Journal of Higher Education Volume XXXI, No. 1, 2001 
Adjusted Participation Rates. Figure 7 shows the changes in adjusted participation rates for women in the field of computer science over the duration of the study. This figure reveals a decline in women's representation in this field, especially at the bachelor level. The likelihood of a female bachelor student majoring in this field compared to that of a male declined from $34 \%$ in $1972-73$ to $20 \%$ in $1994-95$. In other words, the likelihood of a female university student majoring in computer science as compared to that of a man dropped from $34 \%$ in $1972-73$ to $20 \%$ in 1994-95. Put another way, in 1994-95, the female-to male-ratio in this field as compared to the same ratio in all fields was about one half its value in 1972-73. Almost all of this decline took place between 1982 and 1987 following a period of healthy improvement for women in the late 1970 s where their level of participation relative to men's was increasing. Adjusted participation rate at the masters level fluctuated between 1972-73 and 1990 with an overall downward trend from $42 \%$ to $28 \%$ and stabilized in the 1990s. Adjusted participation rate at the doctoral level also fluctuated over the duration of the study, but with a slight overall upward trend from $24 \%$ in $1972-73$ to $29 \%$ in $1994-95$.

The gender gap in computer science enrolment is particularly puzzling. Computer technology is a new field with no long history of sexism to overcome, and the expansion in this field occurred in the early $70 \mathrm{~s}$, almost at the same time as the birth of the feminist movement. At the beginning, the field was open to women, but quickly became maledominated. In 1984 , women constituted $28 \%$ of bachelor degree enrolment, in 1987 they constituted only $20 \%$. And although computer science programs suffered a decline in enrolment of both sexes during this period, men's enrolment quickly bounced back, while women's enrolment never returned to the 1984 level.

Computer Science Enrolment at the Present Time. Of all students on Canadian campuses, only $2.4 \%$ study computer science. This percentage is about the same at all three levels of study. Less than $1 \%$ of women in university major in computer science. Women make up $20 \%$ of computer science bachelor enrolment, $23 \%$ of masters enrolment, and $16 \%$ of doctoral enrolment (Table 4). The female-to-male ratio in bachelor computer science programs is about one fifth of the female-to-male 
Figure 7

Adjusted Participation Rate in Computer Science by Level of Study, Canada 1972-1994

Bachelor Masters

Doctoral

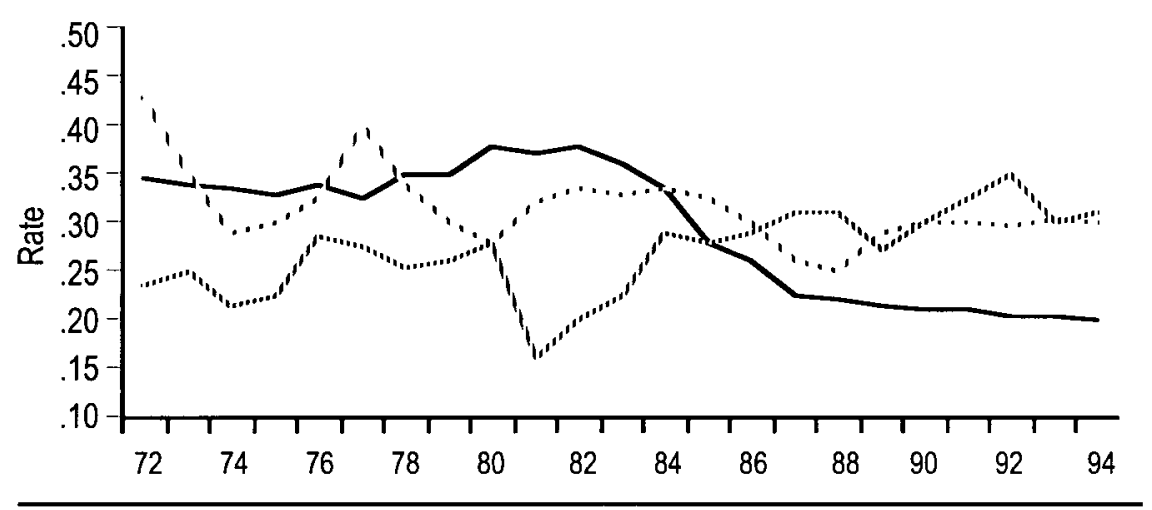

ratio in all fields; that is, the likelihood of a female university student majoring in computer science is about one fifth that of a male.

Women's Movement Through Levels of Study. Table 4 shows that the percentage of women at the masters level $(22.6 \%)$ is higher than that at the bachelor level $(20.2 \%)$. This suggests that the proportion of female bachelor students who move up to a masters program is higher than that of men. Women's share of doctoral enrolment, however, is only $16.2 \%$ indicating that although women do not drop out of education at entry to the masters programs, they drop out at entry to the doctoral programs.

\section{Comparison Between Women's Enrolment in Mathematics, Engineering, and Computer Science}

Enrolment Trends During the Period 1972-73 to 1994-95. During the period under study, the proportion of university students of both sexes majoring in mathematics declined from $2 \%$ to $1.6 \%$, whereas the proportion majoring in engineering increased from $6.3 \%$ to $7.9 \%$ and the proportion majoring in computer science increased from $0.9 \%$ to $2.4 \%$. In other words, while the field of mathematics was losing students 
to other disciplines, the fields of engineering and computer science were attracting more students.

Time trends of women's share of university enrolment in all programs and in each of the three fields are depicted in Figure 8. The most striking feature of this figure is the trend exhibited by the proportion of women in computer science bachelor programs where it increased steadily between 1972 and 1982, then decreased and remained almost stationary from 1987 to the present. In other words, women made good progress during the first ten years considered in this study then turned away from this field in the late eighties and the nineties. This is unlike the trend of women's share of enrolment in engineering bachelor programs where it was steadily increasing throughout the whole period. Women's share of mathematics bachelor enrolment also increased steadily throughout the whole period but the increase is less steep than that seen in engineering. At both masters and doctoral levels, women's participation in all three fields showed some general upward trends which clearly fell below the expansion in their participation in graduate programs in other fields. In general, among the three fields under study, the representation of women is highest in mathematics followed by computer science and lowest in engineering. However, the difference between women's representation in computer science and their representation in engineering bachelor enrolment has been decreasing as a result of the increase in the numbers of women going into engineering programs.

Table 5 displays the gain in women's share of university enrolment at the three levels of study in all programs and in each of the three disciplines in the twenty-three years under study. A number of observations arise from the data in this table:

1. Among the three fields viewed as non-traditional for women, mathematics has always been the least male dominated one.

2. With the exception of engineering bachelor programs, the gain in women's share of university enrolment in the three disciplines at all levels fell short of their overall gain in other programs. Put another way, the proportion of women in engineering bachelor programs has been increasing at a higher rate than their proportion in total university enrolment. This is 
Figure 8

\section{Percentage of Female Enrolment, Canada 1972-94}
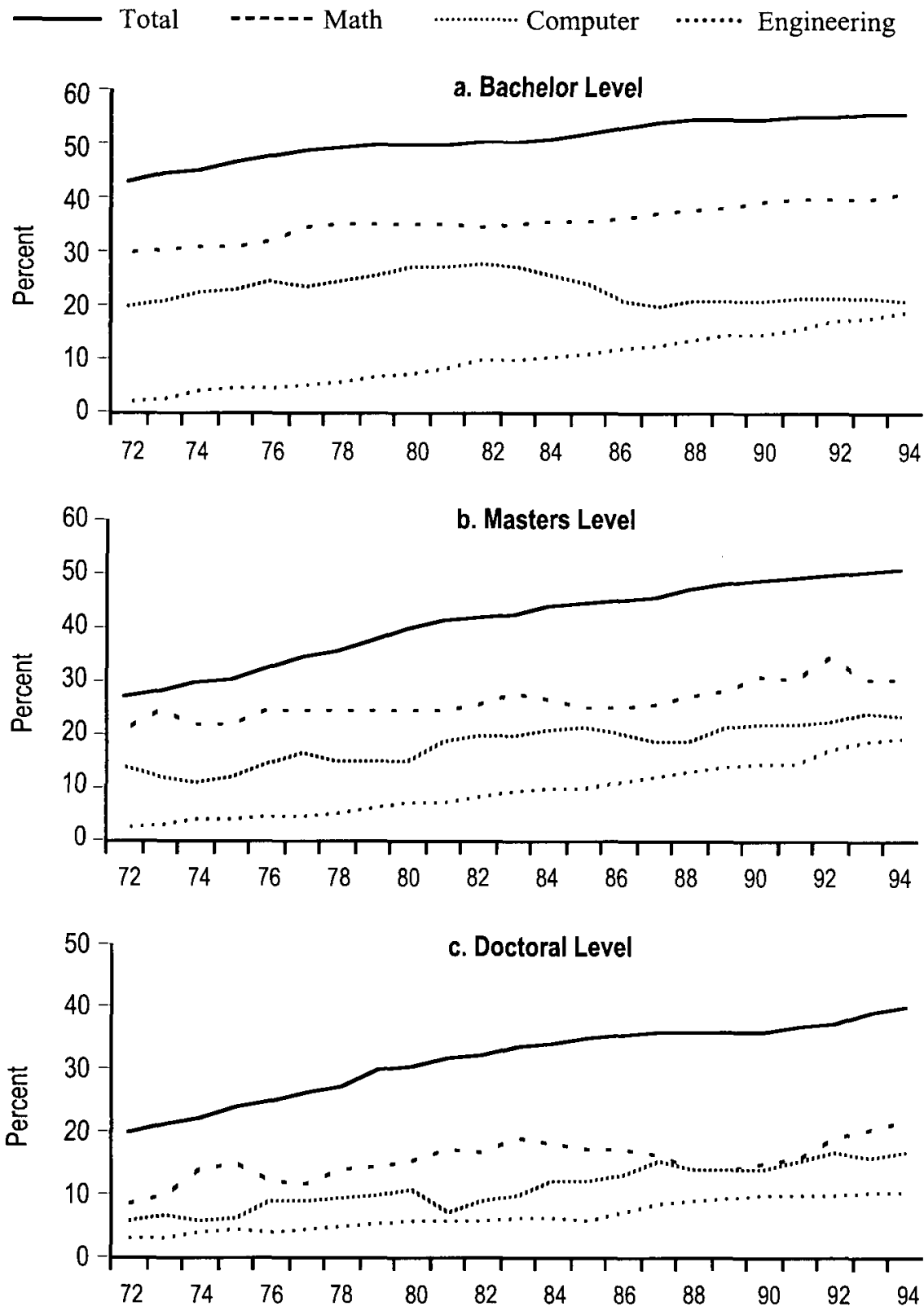

The Canadian Journal of Higher Education Volume XXXI, No. 1,2001 
Table 5

Women's Share of Enrolment by Program and Level of Study, Canada

\begin{tabular}{lrrr}
\hline Discipline and Level & $1972-73$ & $1994-95$ & Gain in \% \\
\hline Mathematics & $28.5 \%$ & $38.2 \%$ & $9.7 \%$ \\
Bachelor & $30.5 \%$ & $40.0 \%$ & $9.5 \%$ \\
Masters & $21.8 \%$ & $30.6 \%$ & $9.4 \%$ \\
Doctoral & $8.4 \%$ & $21.7 \%$ & $13.3 \%$ \\
\hline Engineering & $1.8 \%$ & $17.9 \%$ & $16.1 \%$ \\
Bachelor & $1.7 \%$ & $18.4 \%$ & $16.7 \%$ \\
Masters & $2.3 \%$ & $18.5 \%$ & $16.2 \%$ \\
Doctoral & $2.7 \%$ & $10.4 \%$ & $7.7 \%$ \\
\hline Computer Science & $18.6 \%$ & $20.2 \%$ & $1.6 \%$ \\
Bachelor & $20.2 \%$ & $20.2 \%$ & $0 \%$ \\
Masters & $13.6 \%$ & $22.6 \%$ & $9.0 \%$ \\
Doctoral & $5.3 \%$ & $16.2 \%$ & $10.9 \%$ \\
\hline All Programs & $40.5 \%$ & $54.6 \%$ & $14.1 \%$ \\
Bachelor & $42.6 \%$ & $55.9 \%$ & $13.3 \%$ \\
Masters & $26.7 \%$ & $50.2 \%$ & $23.5 \%$ \\
Doctoral & $19.5 \%$ & $39.0 \%$ & $19.5 \%$ \\
& & & \\
\hline
\end{tabular}

in contrast to the situation in mathematics, computer science, and engineering graduate enrolment. That is, women's representation in these programs has not been as responsive to general social and economic changes as their representation in other programs.

3. The field of computer science has seen a dismal increase in the representation of women. This is particularly true at the undergraduate level where the proportion of women in 1994-95 was exactly the same as it was in 1972-73. 
Review of Figures 2, 4 and 6 reveals the following points:

1. In all 3 fields, the number of students enrolled and parity at the masters level show the most fluctuations over time. This attests to the fact that the masters degree enrolment is difficult to evaluate since it is sometimes awarded as an indicator of progress toward a doctoral degree. Also, some honour students advance to the doctoral level directly âfter attainment of a bachelor degree.

2. In all 3 fields, there is a marked expansion in the gender gap in enrolment in doctoral programs from 1981 to $1993-94$ as a result of a faster rise in men's enrolment. This expansion is more dramatic in engineering and computer science than in mathematics. This was not the case for enrolment in all disciplines where the gender gap in doctoral enrolment remained almost unchanged from 1981 onwards. In other words, while women's doctoral enrolment in all programs was rising at the same rate as men's enrolment, in mathematics, engineering and computer science it was rising at a much slower rate than men's.

3. Except for computer bachelor programs, enrolment in all three disciplines in 1994-95 either dropped or remained unchanged from levels in 1993-94.

Comparison of adjusted participation rates in the three disciplines (Figure 3,5, and 7) indicates that women's representation in engineering relative to their representation in all programs has been steadily increasing over the past two decades which is in contrast to the downward trend exhibited by women's participation in computer science, especially at the bachelor and masters levels, and the slight decline in the mathematics participation rates.

Enrolment at the Present Time. Of university students, $8 \%$ study engineering whereas only $1.6 \%$ study mathematics and $2.4 \%$ study computer science. Women are still under-represented in all three fields but to different degrees. Data in Table 5 show that women's participation in mathematics (38.2\%) is more than twice as high as their participation in engineering (17.9\%) and almost twice as high as their participation in 
computer science $(20.2 \%)$. The disparity in women's representation in these fields persists at the graduate level where they make up $21.7 \%$, $10.4 \%$, and $16.2 \%$ of doctoral enrolment in mathematics, engineering, and computer science, respectively. These proportions are much less than their $39 \%$ share of doctoral enrolment in all fields.

In 1994-95, women's adjusted participation rate at all three levels combined was $21 \%$ in computer science and $18 \%$ in engineering. That is, a female university student is about one fifth as likely as a male student to major in computer science and less than one fifth as likely as a male student to major in engineering. These are much lower odds than seen in mathematics where a female student is half as likely as a male student to major in mathematics. These data do not support the assertion made by some researchers that women choose not to study in engineering or computer science because they want to avoid mathematics.

Women's Movement Through Levels of Study. Data in Tables 2, 3 and 4 also illustrate the different patterns in women's representation at the three levels of study. Assuming that the proportion of students advancing to doctoral study directly after bachelor attainment is similar across all three fields, one can conclude that the pattern of women's advancement through levels of study varies across the three disciplines. While the women's share of mathematics enrolment drops by about 9 percentage points at each higher level of study, the women's share of engineering enrolment is the same at the bachelor and the masters levels, and their share of computer science enrolment actually increases at the masters level. At the doctoral level, women's share of engineering enrolment drops by about 8 percentage points and their share of computer science enrolment drops by about 6 percentage points. In other words, one can conclude that the hurdle impeding women's advancement through levels of study in mathematics lies at entry to the masters level programs, whereas in computer science and engineering it lies at entry to doctoral level programs. These fields should be examined for disciplinespecific factors which might help identify possible road blocks for women at these junctions. 


\section{SUMMARY AND CONCLUSION}

Although women have been pursuing university education in unprecedented numbers, they continue to be under-represented in mathematics, engineering and computer science programs. Improvement in women's representation in these disciplines fell short of the improvement in their representation in other fields. Among the three fields under study, women's representation shows the most improvement in engineering, less so in mathematics and no improvement in computer science. However, the improvement is not sufficient as women are still far from achieving parity in these fields; this is most pronounced in computer science and engineering.

The field of engineering has been gaining students of both sexes from other disciplines. However, the likelihood that a female university student will major in engineering is still less than one-fifth that of a man. Representation of women in the field of computer science as compared to their representation in university education has been declining while there has been little change in mathematics.

Women occupy $20 \%$ of all computer science seats and $18 \%$ of all engineering seats in Canadian universities. These are markedly lower than the $38 \%$ in mathematics. But despite their lower representation in engineering and computer science programs, women in the latter two fields do not seem to drop out from the education system at the masters level at the same rate as women in mathematics do. The proportions of women advancing to graduate studies in all three fields are higher than those in all programs. This denotes that women who do get into these male-dominated fields seem to stick with them. The gender gap in the likelihood of advancing to the doctoral level is much wider in mathematics and engineering than in computer science and other fields.

In mathematics and engineering, women's representation is higher in full-time compared to part-time enrolment at each of the three levels of study. This is in contrast to women's representation in computer science and in all programs.

It is clearly evident from the data presented in this study that women's participation in the three disciplines under study varies a great deal. There are many differences in women's level and trend of 
enrolment in part-time and full-time study, in the size of the gender gap in enrolment and in the rate at which women progress to graduate study. Thus, discipline-specific factors such as curricula, topics, pedagogy, methods of instruction, context, applications, and presentation must influence women's participation in these fields in various degrees. This study shows that many more differences in levels and patterns of women's enrolment exist among scientific and technological disciplines than can be explained by the more general factors discussed in the literature. This author proposes that discipline-specific factors, such as curriculum, course content, instruction methods and context, interact with those general factors and modify their effects on women's participation in these disciplines. Professionals in male-dominated educational disciplines should take responsibility for examining their specific programs with the objective of providing an equitable learning environment for all learners.

\section{References}

Alloway, N. (1995). Foundation stones. The construction of gender in early childhood. Victoria, BC: Curriculum Corporation.

Brush, S. (1991). Women in science and engineering. American Scientist, 79, 404-419.

Canadian Committee on Women in Engineering. (1992). More than just numbers. Ottawa, ON: Canadian Committee on Women in Engineering.

Chipman, S. (1996). Female participation in the study of mathematics: The U.S. situation. In G. Hanna (Ed.), Towards gender equity in mathematics education, an ICMI study (pp. 285-296). Dordrecht: Kluwer Academic Publishers.

Chipman, S.F., \& Thomas, V.G. (1985). Women's participation in mathematics: Outlining the problem. In S.F. Chipman, L. Brush, \& D. Wilson (Eds.), Women and mathematics: Balancing the equation (pp. 1-24). Hillsdale, NJ: Lawrence Erlbaum Associates.

Denton, F., \& Spencer, B. (1992). Modelling and analysis of postsecondary institutional enrolment patterns in Ontario. Hamilton, ON: McMaster University. 
Foot, D., \& Pervin, B. (1983). The determinants of postsecondary enrolment rates in Ontario. The Canadian Journal of Higher Education, 1-22.

Freeman, R. (1986). Demand for education. In O. Ashenfelter \& R. Layard (Eds.), Handbook of Labour Economics, Vol 1. Amsterdam: Elsevier.

Gadalla, T. (1998). Patterns of women's enrolment in university mathematics, engineering and computer science in Canada, 1972-1995. Unpublished doctoral dissertation. Toronto, ON: O.I.S.E.

Harding, J., \& Sutoris, M. (1987). An object-relations account of the differential of boys and girls in science and technology. In A. Kelly (Ed.), Science for girls? Milton Keynes: Open University Press.

Hidi, S. (1990). Interest and its contribution as a mental resource for learning. Review of Educational Research, 60, 549-571.

Hyde, J.S., Fennema, E., \& Lamon, S.J. (1990). Gender differences in mathematics performance: A meta-analysis. Psychological Bulletin, 107, 139-155.

Leder, G.C. (1992). Mathematics and gender, changing perspectives. In D.A. Grouws (Ed.), Handbook of research on mathematics teaching and learning. New York, NY: Macmillan Publishing Company.

Linn, M. \& Hyde, J. (1989). Gender, mathematics and science. Educational Researcher, 18(8), 17-27.

Lawton, C.A., \& Bordens, K.S. (1995). Gender differences in science interests: An analysis of science fair projects. Paper presented at the 61st Biennial Meeting of the Society for Research in Child Development, Indianapolis, IN, 30 March-2 April, 1995. ERIC Document ED 384430.

Pearl, A., Pollack, M., Riskin, E., Thomas, B., Wolf, E., \& Wu, A. (1990). Becoming a computer scientist: A report by the $\mathrm{ACM}$ committee on the status of women in computing science. Communications of the ACM, 33, 47-58.

Rosser, S. (1990). Female-friendly science. Elmsford, NY: Pergamon.

Science Council of Canada. (1982). Who turns the wheel? Proceedings of a workshop on Science Education of Women in Canada (1981). Prepared by Janet Ferguson. Ottawa, ON: Science Council of Canada.

Statistics Canada. (1995). Women in Canada, A statistical report. Third Edition. Ottawa, ON: Statistics Canada.

Stipek, D.J., \& Gralinski, J.H. (1991). Gender differences in children's achievement-related beliefs and emotional responses to success and failure in mathematics. Journal of Educational Psychology, 83, 361-371. 


\section{T.M. Gadalla}

Wiggan, L., Kryger, M., Gamery, R., Morris, M., Clifford, B., \& Getty, B. (1983). Mathematics: The invisible filter. Toronto, ON: Toronto Board of Education.

York University. (1988). Strategies, intervention techniques to retain women in mathematics and science studies. North York, ON: York University. 